\title{
The Impact of Social Media on Business Marketing and Consumer Shopping
}

\author{
Ting Xu \\ Department of Art, Coventry University, Coventry, United Kingdom \\ Email address: \\ xut17@uni.coventry.ac.uk
}

\section{To cite this article:}

Ting Xu. The Impact of Social Media on Business Marketing and Consumer Shopping. International Journal of Literature and Arts. Vol. 8, No. 5, 2020, pp. 272-276. doi: 10.11648/j.ijla.20200805.12

Received: July 25, 2020; Accepted: August 8, 2020; Published: August 18, 2020

\begin{abstract}
In recent years, social media has rapidly become popular around the world. Social media has completely changed the way people communicate and interact in a very short period of time. People use free social media software and websites to keep in touch with friends and make new friends. Now, however, people's concern about social media is not limited to its social nature, and more attention has been paid to the business value it can provide. As a result, companies are also trying to promote their products and services through social media. The potential of social media as a marketing and business platform should not be underestimated. This article will analyze the positive impact of social media marketing, the factors that may affect consumer decisions when they use social media, and the phenomenon of the leakage of citizen privacy in social media platforms to figure out the advantages and disadvantages of social media consumer shopping. In the future, social media will gradually become an important channel of e-commerce, which requires companies to make good use of social media platforms and utilize with new ways of communication to attract consumers to shop.
\end{abstract}

Keywords: Social Media, Marketing, Consumer Decision Making, The Leakage of Citizen Privacy, Future Development

\section{Introduction}

The media is one of the links in the process of communication. It plays an important role in the process of communication, the rapid growth of the powerful Internet, and the rapid spread of smart phones. Specifically, social media have changed the way of people's lives. In recent years, social media have also been used as one of the preferred channels for understanding fashion consumption information and shopping each person can find ways to buy them. New shopping features can also help more businesses promote their goods. This paper will use the method of literature research, based on resources related to communication, sociology, and psychology, and sum up the impact of social media on people. It will analyze from the two aspects of businesses and consumers, and through the analysis of the characteristics of social media in the process of marketing communication, summarize the law and influence of its communication. First of all, this paper will explain the characteristics of social media shopping through literature review. Secondly, it will analyze the positive impact on business and consumption in the process of using social media. Thirdly, it will put forward the privacy disclosure in the process of social media shopping. In the future, with the development of science and technology, social media will provide consumers with more interesting shopping content and personalized shopping experience. However, the privacy leakage caused by the use of social media also needs attention.

\section{Characteristics of Social Media Shopping}

Barnes states that social media is an application that uses interaction and networking to create social capital in a modern way [1]. It benefits from the technology of digital Web 3.0 and has a wide range of communication, interactivity and penetration, which makes companies and young consumers have a strong connection. According to Mikalef, Giannakos, and Pateli, it is more convenient to shop through the Internet because shoppers can access a large number of products at their own time, thus avoiding the transportation required for traditional shopping methods. In 
addition, compared with traditional stores, online stores are available 24 hours a day, so consumers are allowed to browse or shop at any time. The convenience of an online store is one of the core aspects that drive consumer engagement [2]. Many social networking sites now have built-in "purchase keys" such as Twitter, Facebook, Instagram, and Pinterest. Users can buy various goods such as clothes, crafts, and electronics on these social networks. Users of social media have started searching for products on social networking sites or discussing different products on social networking sites, and consumers say that product information posted by their good friends can affect their purchasing decisions.

Social media shopping has three characteristics. Firstly, social media shopping is based on mobile social network. Mobile applications break the restrictions of time and space and provide people with all aspects of information and services. Users can interact with real friends or virtual friends through mobile social applications instantly. This real-time behavior provides a traffic guarantee for social shopping, and a large number of mobile communities with a certain interest are spawned. Secondly, social media shopping converges in the social economy. The verticalized community of interest serves the target group and promotes the emotional communication and deep experience of the users under certain interests. For the commercialization of products, it is necessary to maximize community users' trust and resonance, active participation, and word-of-mouth communication and payment, and to use the influence of the community to explore the economic value of instant mobile network. Thirdly, social media shopping derives from brand marketing. Target groups can be cultivated through brand culture rendezvous, continuous discussions, attention, communication, and consumption. Social media shopping enables mobile Internet users to enhance interpersonal trust in the process of community creation and realize self-emotion and social sharing value. The ultimate goal of social media shopping is to enable a wider group to obtain products.

\section{The Impact of Social Media on Marketing}

Consumption of social media as economic behavior is also a cultural phenomenon in society. Under the development trend of the Internet, mobile social media platforms have become a new front for businesses to advertise. In these platforms, the release of advertising information has far surpassed that of traditional media, and the contents and forms are more abundant. At the same time, modern social media also endow the majority of the audience with more power for autonomous selection. The change in the way information is conveyed also affects the consumption attitude of modern people to a certain extent. According to $\mathrm{Wu}$, consumer purchases are strongly influenced by cultural, social, personal, and psychological factors [3]. In most cases, marketers have no control over these factors, but they must consider them. A combination of factors causes an impact on consumers' attitudes. Under the rapid development of the mobile Internet, the content on social media is more abundant than that on traditional media, and the modes of communication are more diverse, which meets the specific needs of different groups of people. Young consumers can choose the way they have access to information and what kind of information they are exposed to.

Kim and Ko state that social media can have a huge impact on the brand's reputation [4]. With the change of consumers' access to information and their consumption habits, the market share of traditional media is gradually replaced by that of new media. Social media has become increasingly important in brand marketing, and thus using social media as a way of promotion will become the mainstream trend of brand marketing. The report "What's Powering China's Market for Luxury Goods" released by Bain Consulting shows that the rapid growth of leading luxury brands in the mainland market is inseparable from their investment in digital marketing. According to Lannes, the digital marketing budgets of China's top 40 luxury brands have almost doubled since $2015.40 \%-70 \%$ of the budgets are used in WeChat, and the influence of the WeChat platform continues to increase [5]. For example, the consumers of Estée Lauder can use WeChat to book facial treatments, and Coach allows consumers to access coupons and manage their membership cards on the ubiquitous social media platform.

In 2019, Cartier partnered with WeChat to launch an advertisement on WeChat moments. This advertisement unveiled the complete video in person by allowing users to complete the "sliding" operation at the prompt. The total number of interactive clicks of this advertisement was more than six times the average of the market and 300\% higher than that of Cartier in the past. The increase was significant. The main reason was that the "slippery screen" action had brought 2 million slides to the ads. This social media interaction brought obvious benefits to the company.

\section{The Impact of Social Media on Consumer Decision Making}

Online social interactions become increasingly important in today's social life and economy. Social media can not only provide the purchase experience and evaluation of others as a reference when consumers make purchase decisions but also serve as a channel for merchants to get consumer feedback. The convenience of online network and the query ability of product information attract young consumers to understand the relevant information of products through the web, especially the popularity of the products and the comments of other consumers, with which they can judge whether the product is worth buying. The initiative of consumers to conduct social interaction online is increasing. When consumers buy products, they always want to learn from others' evaluation of the products, especially young consumers who tend to share their actual experiences. Social 
media technology provides a platform for consumers to express their opinions, and consumers' opinions can be disseminated to other consumers beyond the constraints of time and space.

According to Cervellon and Lirio, over two billion social media users worldwide have led more and more companies to use social media to communicate with consumers and to conduct customer relationship management and guide word of mouth [6]. The shopping website is an online platform to promote the transaction of goods. The word of mouth on the shopping website refers to the voluntary evaluation of the feeling of the use of the products after the consumer receives the goods [7]. Such evaluations tend to be brief and generally only express the subjective attitude of consumers and do not convey more effective information to other consumers. However, social media platforms are different from shopping websites and not for profit. Their main function is to connect users with common interests, as they are platforms for users to share and exchange ideas and experiences. The information people share on social media is often voluntary. This kind of word-of-mouth information is usually in various forms, with rich contents and high overall quality.

Social media have been widely integrated into the daily communication of consumers [8]. Social media technology enables consumers to express opinions anytime and anywhere. At the same time, public opinions on social media have also shown greater superiority. First of all, for companies, on social media, they can easily analyze the group characteristics of the recipients, namely consumers, and specifically through text, pictures, videos, and other media forms to transmit a variety of information. In the process, companies can look for early adopters or opinion leaders to create word-of-mouth topics, track word-of-mouth communication processes, and collect and analyze word-of-mouth content and trends [9]. It allows companies to understand and grasp consumers' psychology and behavior more effectively and to participate and manage word-of-mouth communication more actively. According to Cheung and Lee, for word-of-mouth recipients, through social media, they can quickly and multi-faceted product information and other people's evaluations, greatly reducing the time cost of information searching before their purchase decision [10]. Moreover, consumers can understand market trends, thereby reduce the uncertainty of purchase and making purchasing decisions more conveniently.

\section{The Leakage of Citizen Privacy in Social Media Platforms}

According to Marwick and Boyd, social network has a huge number of users, so a lot of personal information will be leaked [11]. The availability of social technology enables people to share information about others, further hindering the control of individual privacy. Personal privacy has derived new content based on traditional privacy, such as identity information on registration platform, free registration email for online users. Sometimes social media software requires users to provide personal information, generally including the registered user's name, age, and phone number. It probably also requires other categories such as personal credit and property status, including information about credit cards, electronic consumer cards, and Internet cards. In addition, email address, network name, and network communication protocol address all become private contents. Moreover, more than $50 \%$ of the websites use Flash cookies (personal web browsing trails) to store information about users. Some people are using it to "regenerate" or re-instantiate HTTP cookies deleted by users [12]. The widespread use of cookies in software allows users to browse the web, but during this process, personal preferences are exposed, and the personal browsing history is not easily eliminated.

In the age of information, for some people, online private life has become the main content of personal private life. Generally speaking, in reality, private life and public life have relatively clear boundaries. However, people may have difficulty understanding technical complexity related to the virtual world. The boundary between the public and private sectors is difficult to determine, and the privacy scope in the network environment is controversial. According to Andrews, in the age of social networking, personal privacy is threatened and infringed. People are constantly sharing their lives on social platforms and shopping through social media [13]. In the background of these applications, operators will recommend products a consumer might like by collecting and analyzing users' searching records.

Although people express concerns about their personal information, prevention may reduce the leakage of their own information. However, the observations of actual market behavior indicate that people are not selective enough to protect their data [14]. When the new technology-based media penetrate people's private life in an all-round way, the privacy of individuals faces more risks. Media technology intensifies the violation of personal privacy in two aspects. While social media and Internet technologies are pervasive and continuously updated, the technical possibility of privacy violation is increased. For example, with the technology of the big data, the three-dimensional all-round identification of new media users is realized, which makes the personal information of users more transparent. With the growing number of new media users, the provision of more convenient and personalized services has increased the possibilities for personal privacy violation. Amazon is a successful case of exploiting user data mining opportunities. By collecting and analyzing users' behaviors such as browsing and purchasing, Amazon summarizes their hobbies, behavior habits, and similar behaviors of other users. Thus, products are recommended to the users. Services with such data analysis as its core play a huge role in driving Amazon to grow into a giant enterprise with sales of $\$ 48$ billion in 2011. This kind of service behavior based on user data analysis has been popular in e-commerce activities. On the surface, it realizes the win-win situation of the user's 
personalized experience and the companies' profits, but users are not informed with such behavior, which undoubtedly exposes the data information.

\section{Development in Marketing}

The constant growth and innovation of overseas social media have brought new features, content formats, and dynamic creative capabilities to brands, with the aim of bringing brands closer to their customers. For marketers in charge of cross-border business, a successful marketing strategy involves compellingly attracting the target audience and grabbing their attention in a short period. For example, Facebook and Snapchat have launched new immersive marketing scenarios, including the use of augmented reality. Pinterest and Instagram enhance the functions of shopping. The application of machine learning also provides strong support for more and more platforms.

In addition to the commercial value in commercial advertising, public relations and brand marketing, social media will also be manifested in the business model in the future. It may change the operating and profit model of the industry. In the future, social media may embark on the road of branding and commercial operation and become the main tool for merchants to carry out brand marketing. It is now very common to market through live broadcasts on social platforms in China. Marketing practitioners market their products to consumers through social live broadcast platforms. Consumers only need to input their questions which will be shown on the screen to get real-time commentary from the broadcasters of the companies. They can make payments and purchases on social media if they want to buy this item.

In the future, marketing practitioners will pay more attention to content marketing when using social media for brand marketing. Content marketing will include advertising marketing and video marketing. People will be in an era of information explosion, and they need to think about how to post important information on social media that is short and eye-catching. Brilliant content marketing on social media can not only attract consumers' attention but also build brand image and enhance communication with people so that they can understand a product in a few seconds when watching the video. This trend will become more apparent in the future. Lister et al. state that new media is a new way to represent the world: the media do not always provide new representation possibilities and experiences in ways that are clearly defined (immersive virtual environment, screen-based Interactive multimedia) [15]. Therefore, with the continuous development of technology, there will be many kinds of social media marketing way to use in the future.

\section{Conclusion}

Shopping on social media is undoubtedly more convenient, which is not restricted by time and place. Users can also understand other people's opinions through social interaction.
For marketers, the use of social media strengthens the interaction with consumers, and thus help them increase customer viscosity and gain user reputation. But for network users, while benefiting from the convenience, they also face the risk of privacy disclosure. Therefore, the use of social media in the era of big data will bring both positive and negative impacts to people, so it is essential to solve these negative impacts and create a safe social network environment related to the use of social media. In the future, as augmented reality technology, artificial intelligence and other technologies become more mature, merchants will take a step forward in promoting deeper contact with their consumers.

\section{References}

[1] Barnes, Susan B. "Understanding social media from the media ecological perspective." Mediated interpersonal communication. Routledge, 2008. 28-47.

[2] Mikalef, P., Giannakos, M. and Pateli, A., 2013. Shopping and word-of-mouth intentions on social media. Journal of theoretical and applied electronic commerce research, 8 (1), pp. 17-34.

[3] Wu, S. I., 2003. The relationship between consumer characteristics and attitude toward online shopping. Marketing intelligence \& planning, 21 (1), pp. 37-44.

[4] Kim, A. J. Y. and Ko, E. J., 2010. The impact of design characteristics on brand attitude and purchase intention-focus on luxury fashion brands. Journal of the Korean Society of Clothing and Textiles, 34 (2), pp. 252-265.

[5] Lannes, B., 2019. What's Powering China's Market for Luxury Goods. Bain \& Company.

[6] Cervellon, M. C. and Lirio, P., 2016. When employees don't 'like their employers on social media. MIT Sloan Management Review.

[7] Yoo, C. W., Kim, Y. J. and Sanders, G. L., 2015. The impact of interactivity of electronic word of mouth systems and E-Quality on decision support in the context of the e-marketplace. Information \& Management, 52 (4), pp. 496-505.

[8] Atkinson, S., 2018. WeChat Hits One Billion Monthly UsersAre You One of Them? BBC News.

[9] Babić Rosario, A., Sotgiu, F., De Valck, K. and Bijmolt, T. H., 2016. The effect of electronic word of mouth on sales: A meta-analytic review of platform, product, and metric factors. Journal of Marketing Research, 53 (3), pp. 297-318.

[10] Cheung, C. M. and Lee, M. K., 2012. What drives consumers to spread electronic word of mouth in online consumer-opinion platforms. Decision support systems, 53 (1), pp. 218-225.

[11] Marwick, A. E. and Boyd, D., 2014. Networked privacy: How teenagers negotiate context in social media. New media \& society, 16 (7), pp. 1051-1067.

[12] Soltani, A., Canty, S., Mayo, Q., Thomas, L. and Hoofnagle, C. J., 2010, March. Flash cookies and privacy. In 2010 AAAI Spring Symposium Series.

[13] Andrews, L., 2012. I know who you are and I saw what you did: Social networks and the death of privacy. Simon and Schuster. 
[14] Norberg, P. A., Horne, D. R. and Horne, D. A., 2007. The privacy paradox: Personal information disclosure intentions versus behaviours. Journal of consumer affairs, 41 (1), pp. 100-126.
[15] Lister, M., Giddings, S., Dovey, J., Grant, I. and Kelly, K., 2008. New media: A critical introduction. Routledge. 